\title{
THE EFFECTIVINESS OF MINI-CEX TOWARDS CLINICAL COMPETENCY ACHIEVEMENT IN NEUROLOGICAL EXAMINATION OF CLINICAL PRACTICE NURSING STUDENTS
}

\author{
Amila", Eva Kartika Hasibuan, Lasma Rina Sinurat \\ Pharmacy Faculty\&Health Sciences, Sari Mutiara Indonesia University \\ Jalan Kapten Muslim No.79 Medan 20134 \\ Email*: mila_difa@yahoo.co.id
}

\begin{abstract}
Introduction: Mini-CEX (Mini Clinical Evaluation Exercise) is a method of evaluation to assess the clinical skills of students through direct observation and provide constructive feedback. The aim of this study was to evaluate the effectiveness of Mini-CEX towards clinical competency achievement in neurological examination of clinical practice nursing students at General Hospital Medan.

Methods: The research design was quasi experiment with the post-test only with control group approach. The samples were 60 respondents who divided into two groups: 27 respondents in the control group, and 33 respondents in the intervention group. Samples were chosen using the total sampling method.This study used the Mini-CEX to evaluate competency of nursing students and firstly developed in Indonesian by Nursing Study Program in Muhammadiyah University of Yogyakarta. The data were analyzed by descriptive and Mann Whitney test.

Results :The study showed that mean score of neurological examination competence in the intervention group (77士8.33) was higher than the control group (68.19 \pm 7.53$)$. There were significant differences of the clinical competency between two groups of samples with $p$ value $0.000(p<0.05)$.

Conclusions : Clinical practice nursing students competency were improved using Mini-CEX method. It is recommended that the nursing study program use Mini-CEX method to evaluate clinical nursing practice so that student's learning competency is increasing.
\end{abstract}

Key words : Mini-CEX, clinical competency, evaluation, neurological examination

\section{INTRODUCTION}

Curriculum of internship program in nursing education in Indonesia has undergone change, from discipline based curriculum into competency based curriculum. Competency based curriculum in nursing internship program comprised of $60 \%$ core clinical practice related creditsfrom its total credits (Permendikbud RI, 2014). Thus, this change requires alternation in terms of learning method as well as evaluation method.

Aparently, nursing students still find difficulty in developing professional skills during their clinical internship. This difficulty might be caused by various factors, such as inadequacies of role model from clinical mentor, variety of advisory methods, technical training from clinical mentor, facilities including tools and infrastructures which support clinical learning process and clinical teaching method (AIPNI, 2014). These inadequacies might lead to the failure of clinical competence achievement as a professional nurse which is in accordance with the standard in nursing education. Failure in achieving clinical competence will make students incompetent in treating patients, performing nursing procedures, and completing tasks in hospital. The quality of students' skills is seemingly determinitive to healthcare provider quality in the society, since nursing students will become health providers after they accomplish their nursing education. These opportunities shoud be maximized through an appropriate evaluation method, so that students will be encouraged to improve their competence gradually (Sudarso, Rahayu\& Suhoyo, 2015).

In order to understand whether or not the students are able to apply the competencies, it is necessary to assess or evaluate those competencies (Iryani, 2012). The evaluation results of students' clinical performance should be well organized, sustainable, and able to provide opportunities to show their professional skill, so that the competencies that should be gained in each phase or stage will be achieved (Nursalam, 2011). 
Neurological physiology examination is an examination aims to figure out neurological health status, normal and abnormal result of physical examination, as well as to support diagnosis. Hence, it is expected that students are competent in performing neurological examination. In order to be skillful in these competencies, it is necessary to conduct clinical evaluation which can also increase students' motivation to learn.

There are various clinical evaluation methods in nursing internship program, such as observation, journal report, viva-vace, objective structured clinical examination (OSCE), mini-CEX, multisource feedback (MSF), case based discussion (CBD), and direct observation of procedural skills (DOPS) (Nursalam, 2011; Carr, 2012). This clinical evaluation methods is thevalidity is still being considered, attitude are difficult to asses, need more than one hourso that cause the patients are inconvenience, does not reflect the general, the assessment is performed only once by one assessor,no observation and feedback directly so that clinical preceptor does not recognize the advantages and disadvantages of students (Dornan, Karen, Scherpbier Spencer, 2011; Iriani, 2012; Norcini et al., 2007).

However, seemingly, there is yet an evaluative method which significantly contributes in improving nursing student competence. Perception disceprancies in clinical learning and the absence of evaluation method in nursing clinical practice are often argued to be the reasons.

It is argued that mini-CEX is the most effective evaluation method since it has greater accuracy in assessing students' clinical competence. Mini-CEX first developed by American Board of Internal Medicine (ABIM) in 1972 and 1978 by the Australian Medical Council (AMC) to assess graduates of medicine(Nair,et al 2008).Mini-CEX is not only applied in medical internship program, but also in nursing internship program.It has been implemented in Taiwan and Indonesia in the first 2011. The university first apply MiniCEX of clinical education program in Indonesia wasMuhammadiyah University of Yogyakarta(Djuria\& Afandi, 2013).

Mini Clinical Evaluation Exercise (Mini-CEX) is one of the assessment methods that provide feedback immediately afterwards. In Mini-CEX, the clinical supervisor can provide feedback to the student based on direct observation. Students have the opportunity to be assessed in various clinical settings and receive feedback by multiple assessors. The Mini-CEX is a valid evaluation method that is used to assess students' clinical competence in clinical practice phase in order to prepare student to provide excellent clinical care service (Norcini, et al., 2007).

According to WHO (2009), mini-CEX is an evaluation method that provides great opportunities for students to improve their skills when they deal with many patients and various cases in which students are directly observed by their evaluator (Ansari et al., 2013; Kuo et al., 2013). Besides, at the end of the evaluation, students will get feedback from their evaluator related to their progress in conducting clinical practices (Holmboe et al., 2004; Norcini et al., 2007). Mini-CEX can also help clinical preceptor to apply their academic knowledge technically, improve self confidence of clinical preceptor as well as performance consistency (Huang, 2015).

There are at least three advantages of the implementation of mini-CEX in evaluating clinical practical progress of nursing students. First, it can be conducted in various location settings. Mini-CEX can be done many times in different settings and cases, so that it may provide more experiences for students to perform clinical intervention to patients which eventually may improve students' performance (Norcini et al., 2007; Lima et al., 2011). Second, it is argued that the clinical evaluator will find satisfaction using this evaluation tool. Third, evaluators are able to give constructive feedback related to students' weaknesses encountered during evaluation. Furthermore, this feedback can be used as guidance to correct or improve their weaknesses. Thus, it is argued that the above mentioned strengths of mini-CEX may improve students' learning and professionalism in providing healthcare service to patients. Hill \& Kendall (2007) found that nursing students in their study reported that mini-CEX increased their study time and motivation as the result of repetitions in mini-CEX.

The assessment in mini-CEX is initiated through carrying out observation by evaluator when nursing students interact with their patient for around 15 minutes. After that, for around 5 minutes, the evaluator gives constructive feedback to students related to their achievement. The result from that 
evaluation is accounted in assessment sheet which comprised of 7 evaluation components such astherapeutic communication skill, physical examination skill, clinical professionalism, nursing intervention skill, consultation or health education, organization/ efficiency, and general nursing clinical competency.

This study aims to investigate the difference of students' competence evaluation results between the control group and the intervention group after the implimentation of mini-CEX.It is expected that the present study can be used as a model of student clinical competency evaluation through mini-CEX during nursing internship programto improve clinical competence of nursing students in their internship program after mini-CEX evaluation method developed. The result of mini-CEX evaluation can also be used as basic information to directly provide constructive feedback on students' performance.

\section{METHODS}

This was a quasi experimental study using post test only with control group design. The population were all nursing students of internship program who were conducting clinical pratice of medical surgical nursing in General Hospital, Medan, comprised of 27 students in control group (group B) and 33 students in intervention group (group A) who were selected as samples through total sampling technique.

This study was conducted after the researcher had been granted the approval from Ethics Committee of University of North Sumatera (number :1210/V/SP/2017, date issued : May 24, 2017) and Chief of Training and Education Center at Adam Malik General Hospital, Medan (DM.01.04/II.2/2020/2017, date issued: June 13, 2017). The present study was carried out by emphasizing ethical issues and considering various aspects, such as self determination, privacy and anonymity, beneficence, maleficence, justice.

The present study took place at General Hospital Medan, since it was the location of nursing students undergoing their clinical internship program in medical surgical nursing. A total of 8 rooms comprised of 4 rooms to conduct evaluation on interventiongroup and 4 rooms on the control group, were the locations employed in the study. This study was carried out from July $16^{\text {th }}$ until July $29^{\text {th }}, 2017$.

There were two instruments used in this study. First, rating scale such as cranial nerve examination that was frequently used to evaluate the clinical practical of nursing students in Nursing Internship Program atSari Mutiara Indonesia University. Rating scale was used to collect evaluation data from the control group. Second, mini-CEX assessment sheet that was developed by Norcini et al. (2003), involving the identity of student and evaluator, scale ranging from 1 to 9. This scale categorized students' performance into "remedial", " meet expectations", "superior". Components evaluated in this tool were exam performing skill, intervention procedure, clinical decision, communication skill, professionalism, organization, and competence in giving treatment to patients. The students were categorized "competent" if their score was $\geq 75$, and "incompetent" if their score was $\leq 75$. At the end of the assessment, students' satisfaction as well as clinical evaluator's toward mini-CEX tool and traditional evaluation method were evaluated. The scale of satifcation ranged from 1 - 9 (low - high).

The validity and reliability of mini-CEX have been examined by Djuria \& Afandi (2013) in their study about "the development of mini-CEX as an evaluation tool in nursing internship program". Content validity test has been carried out by a group of experts with experience in research and education, the team comprised of 2 experts from nursing education and 2 experts from medical education. On the other hand, the reliability score was 0.988 implying that the instrument had a high internal consistency value.

Interrater test of mini-CEX tool was performed by 3 researchers on 10 patients with neurological problems at Sari Mutiara General Hospital. Kappa coefficient value of each researcher was 1,000 with $p=(\alpha=0,05)$ indicating that there was no different perception in mini-CEX evaluation tool. The validity and reliability calculations of miniCEX as evaluation instrument were also conducted by several researchers from several medical education centers. Data analysis was performed through univariate 
and bivariate calculations. Univariate analysis was employed to figure out the frequency distribution of each variable. Bivariate analysis was performed through Mann Whitney Test, because the data was abnormally distributed.

\section{RESULTS}

Based on the data in table 1, it can be seen that the majority of the respondents in control group is female $(62.9 \%)$ and $37.04 \%$ are male. Based on the result of competence evaluation in performing neurological examination, most of respondents in control group is incompetent $(70.37 \%)$ and $29.63 \%$ are competent. In contrast, most of the respondents in the intervention group is competent in conducting neurological examination $(81.82 \%)$ and $18.18 \%$ are not competent.

Table 2 shows that the average age of the nursing students in the control group is 22.67 years of age $(\mathrm{SD}=1.109)$, with the youngest age is 21 years and the oldest is 25 years. On the other hand, the average age of nursing students in the intervention group is 22.48 years $(\mathrm{SD}=0.566)$, with the youngest age is 22 years and the oldest is 24 years old. The mean score of neurological examination competence is 68.19 ( $\mathrm{SD}=7.53$ ), the lowest score is 58 and the highest score is 82 . In contrast, the mean score of neurological examination competence in the intervention group is $77(\mathrm{SD}=8.325)$, the lowest score is 54 and the highest score is 89 . In terms of satisfaction on mini-CEX, the mean score of the nursing students in the intervention group is 7.58 ( $\mathrm{SD} \mathrm{0.936);} \mathrm{the} \mathrm{lowest} \mathrm{score} \mathrm{is}$ 6 and the highest score is 9. The score of nursing students in the control group toward satisfaction on traditional evaluation method is $6.22(\mathrm{SD}=0.847)$; the lowest score is 4 and the highest score is 8 . Furthermore, the mean score of the clinical evaluators' satisfaction on mini-CEX is $7.09 \quad(\mathrm{SD}=$ 1.156); the lowest score is 5 and the highest score is 9; whereas the mean score of the clinical evaluators' satisfaction on the traditional evaluation method in the control group is $6.3(\mathrm{SD}=0.542)$; with the lowest score is 5 and the highest score is 7 .

From Table 3, it can be seen that based on the statistical analysis using Mann Whitney Test, $p$ value is 0.000 at $\alpha=0.05$. It may indicate that there was significantly different result of neurological examination competency between nursing students in the control and those in the intervention group.

Data in Table 4 shows that the statistical score through Mann Whitney Test is $p=0.000$ at $\alpha=0.05$, indicating that the satisfaction toward neurological examination of nursing students and clinical evaluators between control group and intervention group is significantly different.

Table 1. Respondent Distribution Based on Sex, Skill Evaluation at Nursing Internship Program $(\mathrm{n}=60$ respondents)

\begin{tabular}{|c|c|c|c|c|c|c|}
\hline \multirow{2}{*}{ Variables } & \multicolumn{2}{|c|}{$\begin{array}{c}\text { Control } \\
(n=27)\end{array}$} & \multicolumn{2}{|c|}{$\begin{array}{c}\text { Intervention } \\
\quad(n=33)\end{array}$} & \multicolumn{2}{|c|}{ Total } \\
\hline & $\sum$ & $\%$ & $\sum$ & $\%$ & $\sum$ & $\%$ \\
\hline \multicolumn{7}{|l|}{$\overline{\operatorname{Sex}}$} \\
\hline Male & 10 & 37.04 & 9 & 27.27 & 19 & 31.67 \\
\hline Female & 17 & 62.96 & 24 & 72.73 & 41 & 68.33 \\
\hline Total & 27 & 100 & 33 & 100 & 60 & 100 \\
\hline \multicolumn{7}{|c|}{ Neurological Examination } \\
\hline Competent & 8 & 29,63 & 27 & 81,82 & 35 & 58.33 \\
\hline Incompetent & 19 & 7037 & 6 & 18,18 & 25 & 41.67 \\
\hline Total & 27 & 100 & 33 & 100 & 60 & 100 \\
\hline
\end{tabular}


Table 2.Respondent Distribution Based on Age, Skill Evaluation, Satisfaction of Nursing Students and Evaluators at Nursing Internship Program ( $n=60$ respondents)

\begin{tabular}{lccccc}
\hline \multicolumn{1}{c}{ Variables } & Mean & SE & SD & Min & Max \\
\hline Age & & & & & \\
\hline Control & 22.67 & 0.214 & 1.109 & 21 & 25 \\
\hline Intervention & 22.48 & 0.098 & 0.566 & 22 & 24 \\
\hline $\begin{array}{l}\text { Skill Evaluation } \\
\text { Control }\end{array}$ & 68.19 & 1.449 & 7.53 & 58 & 82 \\
\hline Intervention & 77 & 1.449 & 8.325 & 54 & 89 \\
\hline Nursing Students' Satisfaction & & & & \\
\hline Control & 6.22 & 0.163 & 0.847 & 4 & 8 \\
\hline $\begin{array}{l}\text { Intervention } \\
\text { Evaluators' Satisfaction } \\
\text { Control }\end{array}$ & 7.58 & 0.163 & 0.936 & 6 & 9 \\
Intervention & 6.3 & & & & \\
\hline
\end{tabular}

Table3.Result Analysis of Skill/ Competence Evaluation Difference on Neurological Examination between Control Group and Intervention Group at Nursing Internship Program

\begin{tabular}{|c|c|}
\hline $\mathbf{Z}$ & Sig.(2-tailed) \\
\hline-3.78 & 0.000 \\
\hline \multicolumn{2}{|c|}{$*$ Significant at $\alpha<0.05$} \\
\hline
\end{tabular}

Table 4. Result Analysis of Satisfaction Difference on Neurological Examination between Nursing Students in Control Group and Intervention Group at Nursing Internship Program

\begin{tabular}{|c|c|}
\hline $\mathbf{Z}$ & Sig.(2-tailed) \\
\hline \multicolumn{2}{|c|}{ Nursing Students' Satisfaction } \\
\hline$-6.276 \quad 0.000$ \\
\hline \multicolumn{2}{|c|}{ Evaluators' Satisfaction } \\
\hline$-5.457 \quad 0.000$ \\
\hline
\end{tabular}

\section{DISCUSSIONS}

1. Clinical competence skill of nursing students of Nursing Internship Program in Carrying Out mini-CEX and Traditional Evaluation Methods

This study compared the effect of new evaluation method and conventional evaluation method on clinical competence of nursing students in internship program. It was obtained that most of nursing students whose clinical competence evaluated through mini-CEX was skillful. This study was consistent
withMoghadam et al. (2016) showing that the mean of final score of the experimental group (mini-CEX) is significantly higher than that of the control group.

The implementation of clinical learning is an authentic and realistic experience for nursing students to learn professionalism. This clinical internship provides opportunities for students to obtain real experience in achieving the competencies that are necessary in certain clinical tasks. To ensure that nursing students achieve the standard clinical compentencies is the objective of nursing internship program. During this phase, the students get 
opportunities to directly interact with their patients and learn how to behave and act as a professional nurse. Competencies, such as physical examination, effective communication with patients and professional behaviours are crucial to be trained in this clinical internship stage.

The competencies mentioned above are the keys for a nurse to give appropriate nursing intervention to their clients in order to improve the quality of nursing care service and help in their client health recovery since nursing competence might contribute significatly on clients' physical and psychological health. Students' opportunities should be provided greatly by determining appropriate evaluation method so that students will be motivated to improve their skills continuously (Sudarso, Rahayu \& Suhoyo, 2016).

Mini-CEX evaluation among nursing students of Nursing Internship Program was carried out by clinical evaluator through observing students when they interact with the neurological patients for around 15 minutes. After that, for around 5 minutes, the clinical evaluator gave constructive feedback to the students toward their achievement. The results of this neurological examination, were accounted in assessment sheet which comprised of 7 assessment competencies, such as therapeutic communication skill during neurological examination, physical examination skill, clinical professionalism, nursing intervention planning, health consultation or education, organization/ efficiency, and general clinical nursing competency.

Several students reported that mini-CEX improved their study time and motivation as the result of repetitions in mini-CEX. The students were aware that they would be observed and evaluated on anamnesis skill, physical examination, and interaction with patient, so that students ought to spend longer time to practice performing anamnesis and neurological physiology examination.

The result obtained from the observation was that through the implementation of miniCEX, students became more motivated to achieve the clinical competence, understand learning objectives and expected standards/ criteria to utilize the feedbacks they received to do self reflection and improve their performance in order to accomplish the appointed learning objectives.
Consistent and sustainable direct observation will cause students' competence or competency measurable (Norcini \& Burch, 2007). In regard to the importance of observation in clinical skill assessment, Hauer (2007) argues that mini-CEX is used to directly observe students when they perform clinical competencies, particularly anamnesis and physical examination. Besides, Holmboe et al. (2004) also advocates that, direct observation by clinical evaluator is a vital process to evaluate students' clinical competencies. A consistent and sustainable evaluative process during clinical internship program, in long term period of time, will bring effects on students' professionalism development.

Moreover, Dwi (2010) explained that the traditional instrument, rating scale, till date only implements evaluation on knows and knows how levels, whereas if the evaluation is only implemented in these levels the students cannot be considered competent, particularly in performing neurological examination.

\section{Differences of clinical competence evaluation of nursing students between the control group and intervention group}

The research result showed that there was evaluation result difference on control group's clinical competence and that of intervention group. This result supported the finding from the study conducted by Moghadam et al. (2016), showing that there was mean score difference of anestesiological students' clinical competence between the control group and intervention group.

The evaluation instrument used in the control group was rating scale. It was a traditional evaluation tool commonly used to assess students' clinical competence during their internship program. The students were only evaluated at the end of the clinical internship, i.e. at week 8 . This evaluation method apparently showed that many students were not competent in performing neurological compared to intervention group that was evaluated using mini-CEX tool.

To the intervention group, the clinical evaluation was conducted several times to provide opportunities to students to improve their weaknesses in carrying out procedures of neurological examination. Constructive feedback was also given by the clinical 
evaluator at the end of evaluation session, in which it helped the students to figure out their mistakes or weaknesses based on the seven evaluation criteria. After giving corrective feedback to students, the evaluator would provide explanation to students on how to improve their performance. This finding was in accordance with the explanation given by Rahayu and Suhoyo (2015) suggesting that opportunities that nursing students received in each practical stage were greatly used by determining an appropriate evaluation method so that students would be motivated to improve their performance continously.

In mini-CEX, the clinical supervisor can provide feedback to the students based on direct observation. Students have the opportunity to be assessed in various clinical settings and receive feedback by multiple assessors(Sudarso, Sudarso, Rahayu \& Suhoyo,2016).Thecorrective feedbacks given communicatively by the clinical evaluator was to provide better understanding to students that a nurse should be able to act professionally. Besides, constructive feedbacks may also provide information to students about the gaps between the actual and standard clinical performances they should have (Ramani \& Leinster 2008; Cantillon \& Sargeant 2008).

In this study, it is argued that mini-CEX can improve students' clinical learning through information about their own competency progress or weakness, suggestion about the necessary learning materials and sources which can facilitate students' self learning, and motivation to have appropriate learning activities (Norcini \& Burch, 2007). In miniCEX evaluation, students are aware that they will be observed and evaluated on anamnesis competency, physical examination, and interaction with patients, so that they will spend more time to practice anamnesis and physical examination.

Mini-CEX is designed to identify the strengths and weaknesses of students' clinical performances based on direct observation during students' interaction with their patients. Based on this information, the evaluator can give positive feedbacks to further develop and improve students' clinical competencies (Hill $\&$ Kendall 2007; Norcini \& Burch 2007).

The result obtained from this study was also in accordance with the result of the study on the implemention of mini-CEX in Residence level which showed that mini-CEX gave constructive effect on Residence's learning (Malhotra, Hatala \& Courneya, 2008). Supported by the research result of Habibi et al. (2013), it showed that there was mean score difference between the that of the experimental group and control group.

Mini-CEX was conducted by involving various neurological cases, so that the nursing students were exposed to various patients and diagnosis/ nursing care problems. It is expected that this kind of interaction will positively impact students' perceptions of interaction and service provision to the patients. Because generally, patients who are accompanied by their family, will also affect the relationship between students and patients' family members. Mini-CEX built the good relationship between students and lecturer, as well as being a means of supervision and modeling of the implementation of clinical skills.

Mini-CEX stimulated students' internal process, including self-reflection, emotional response, and motivation. These internal processes encouraged the students to take action or do a follow-up on In addition, there was also an external factor, namely consequences, which also influenced the students' reaction to the follow-up on feedback. In the end, this action caused several learning effects that resulted in the students' increased self-efficacy, attitude, knowledge and clinical skill.(Sudarso et al., 2016)

The result showed that mean score for satisfaction with Mini-CEX was higher than conventional methods. Students believed that Mini-CEX method was effective and more received. This study was consistent with Husaini, et al (2012) reported a high mean score for satisfaction with this Mini-CEX $(67.8 \pm 12.5) \quad(p=0.973)$ and this method was found to be very useful for educating and motivating students. Mansourian et al (2013) show that the mean score of students satisfaction with OSPE (74.3) was higher than that of conventional method (49.7), which was statistically significant $(\mathrm{p}<0.0001)$.

Some of the limitation of this study were the researcher did not compare the Mini-CEX or conventional methods before intervention, student's anxiety during assesment and unwillingness of some students to perform new assesment methods. 


\section{CONCLUSIONS RECOMMENDATIONS}

AND

This study showed that Mini-CEX significantly affecttheclinical competence skill of Nursing Internship Program.

Mini-CEX is believed to be a method that promote the strengthen and covering the weakness largely by providing feedback and innovative technique. It is suggestion for Nursing Study Program use mini-CEX as a model of student clinical competency evaluation during nursing internship program to improve clinical competence of nursing students in their internship program.

\section{REFERENCES}

AIPNI, 2014. Materi Pelatihan Preceptorship (tidak dipublikasikan). Yogyakarta : STIKes Almaata (in Bahasa Indonesia).

Ansari, A.A., Ali, S.K and Donnon, T. 2013. The construct and criterion validity of the Mini-CEX : a met-analysis of the published research.Academic Medicine Journal. 88 (3): 0-0.

Djuria, S.A., \& Afandi, M. (2013). Development of measurement tool Mini-CEX (Mini Clinical Evaluation) as an evaluation tool of nursing students in teaching hospital of Universitas Muhammadiyah Yogyakarta. GSTF International Journal of Nursing and Health Care (JNHC).1(1): 127-132.

Dornan T, Karen, Scherpbier A, Spencer, J. 2011. Medical Education Theory and Practice. Elsevier. London.

Habibi, H., Khaghanizade, M., Ebadi, A., \& Sayedmazhari, M. 2013. Comparison of the Effect of Modern Assesment Methods (DOPS and Mini-CEX) with traditional method on Nursing students'Clinical Skills : A Randomized Trial.Iranian Journal of Medical Education. 13(5) :364-372.

Huang, S. Y. (2015). The Experience Of MiniClinical Evaluation. BMJ Open, A1A53.

Holmboe, E.S., Yeps, M., Williams, F., Hout, S.J. (2004). Feedback and mini clinical evaluation exercise.J. Gen. Intern. Med. 19 (8): 558-561.

Iryani, D. (2012). Tinjauan Pustaka Mini Cex : Metode Penilaian Performa. Majalah Kedokteran Andalas, 36(1), 23-28.
Kuo, C.L., Shou, J.P., Maw, S.L., Chih, W.Y and H, P.K. (2013). Develompment and implementation of a mini-clinical evaluation exercise (Mini-CEX) program to asses the clinical competencies of internal medicine residents: from faculty development to curriculum evaluation. BMC Medical Education. 13 (13): 1472-1476.

Lita, B.F. (2013). Comparison of perceptions of nursing internship program and preseptor on Mini-CEX implementation in Education Hospital. Underthesis. Muhammadiyah University of Yogyakarta.

Moghadam, F.A., Sahebalzamani, M., Fatemah, M., Farahani, H., \& Gharabagh, Z.A. (2016). A comparative analysis of the effect of Mini-CEX and conventional assesment methods on clinical skill ini anesthesiology students of School of Paramedicine, Hamedan University of Medical Sciences. Journal of Advances in Medical Education (JAMED). 1 (3): 60-68.

Nair, BR, McGrath, BP, Parvathy, MS, Kilsby, EC, Wenzel.J.,Frank, IB, et al. (2008). The Mini Clinical Evaluation Exercise(Mini-CEX) For Assessing Clinical Performance of InternationalMedical Graduates. Medical Education.Vol.189

Norcini, J.J., Blank, L.L., Duffy, D., Fortna, G.S. (2003). The mini cex: a method for assesing clinical skills.Ann.Intren. Med. 138 (6): 476-481.

Norcini, J and Burch, V. (2007). Workplacebased assessment as an educational tool; AMEE guide no.31.Medical teacher. 29 (6): 855-871.

Nursalam. (2011). Manajemen Keperawatan Aplikasi dalam Praktik Keperawatan Profesional. Edisi 3. Salemba

Permendikbud RI. (2014). Standar Nasional Pendidikan Tinggi. Peraturan Menteri Pendidikan dan Kebudayaan No. 49 Tahun 2014. Jakarta.

Sudarso, S., Rahayu, G. R., \& Suhoyo, Y. (2016). How does feedback in mini-CEX affect students' learning response? International Journal of Medical Education, 7, 407-413. https://doi.org/10.5116/ijme.580b.363d 